\title{
ESTUDO DOS EFEITOS DO BRANQUEAMENTO NA RETENÇÃO DE CAULIM E NAS PROPRIEDADES DO PAPEL ${ }^{1}$
}

Ivan Rodrigues dos Santos², Gustavo Ventorim ${ }^{3}$, José Cláudio Caraschi e Jaqueline Silveira Comelato Favaro $^{4}$

\begin{abstract}
RESUMO - O objetivo deste estudo foi verificar a influência do emprego de sequências de branqueamento na retenção de diferentes teores de caulim e nas propriedades do papel formado. Foram adotadas três sequências de branqueamento do tipo ECF para uma mesma polpa de eucalipto pré-deslignificada com oxigênio, sendo elas: $\mathrm{D}(\mathrm{E}+\mathrm{P}) \mathrm{DP}$ (referência, ECF), $\mathrm{A}_{\mathrm{HT}} \mathrm{D}(\mathrm{E}+\mathrm{P}) \mathrm{DP}(\mathrm{A}-\mathrm{ECF})$ e $\mathrm{A}_{\mathrm{HT}} \mathrm{D}(\mathrm{E}+\mathrm{P}) \mathrm{P}(\mathrm{ECF}-$ Light $), \operatorname{com} 20 \mathrm{~kg} / \mathrm{t}$ a.s. de peróxido de hidrogênio no estágio final. As polpas foram branqueadas até a obtenção de $90 \pm 0,5 \%$ ISO de alvura. Posteriormente, foi realizada a substituição da fibra por carga de caulim na proporção de $0 \%$ a $35 \%$, com intervalos de $5 \%$, para cada polpa. As folhas de papel, formadas com gramatura de $60 \mathrm{~g} / \mathrm{m}^{2}$, foram caracterizadas quanto às propriedades físicas e mecânicas. Também foram analisadas as dimensões das fibras obtidas em cada sequência de branqueamento. Os resultados indicaram que a sequência de branqueamento influencia tanto na retenção, devido ao tamanho das fibras e ao teor de finos gerado por sequência de branqueamento, quanto nas propriedades físicas e mecânicas do papel para cada teor de caulim. A sequência ECF-Light apresentou melhor retenção, e o papel produzido com a polpa obteve melhores resultados de lisura, enquanto a sequência $\mathrm{OA}_{\mathrm{HT}} \mathrm{D}(\mathrm{E}+\mathrm{P}) \mathrm{DP}$ mostrou maior resistência interna e maior resistência à compressão. A polpa ECF exibiu melhores resultados de índice de rasgo, de viscosidade, de rendimento e de qualidade de fibra.Concluiu-se que, quanto maior a quantidade de caulim no papel, menor a sua resistência mecânica.
\end{abstract}

Palavras-chave: Caulim; Retenção; Branqueamento.

\section{ANALYSIS OF PULP BLEACHING SEQUENCES IN THE RETENTION OF KAOLIN AND IN THE PROPERTIES OF PAPER}

\begin{abstract}
The aim of this study was to investigate the influence of different bleaching sequences at different amounts of kaolin in paper properties. To do that, three different ECF bleaching sequences were taken to the same $\mathrm{O}_{2}$-delignified eucalyptus pulp, these being $D(E+P) D P($ reference $E C F), A_{H T} D(E+P) D P(A-E C F)$ and $A_{H T} D(E+P) P(E C F-L i g h t), 20 \mathrm{~kg} / \mathrm{t}$ o.d. hydrogen peroxide in the final stage. The pulps were submitted to bleaching to obtain $90 \pm 0.5 \%$ ISO brightness. After that, the replacement of the fiber by filler kaolin type in a proportion of $0 \%$ to $35 \%$ in increments of $5 \%$ were made for each pulp. The pulp sheets formed with a weight of $60 \mathrm{~g} / \mathrm{m}^{2}$ were characterized for physical and mechanical properties. Fiber dimensions obtained for each bleaching sequence were also analyzed. The results showed that the bleaching sequence influence on both the retention due the size of fibers and the fines content generated by each bleaching sequence as well as the paper physical and mechanical properties for each kaolin content. The ECF-Light sequence showed better retention and paper produced with the pulp showed a better smoothness, while sequence $O A_{H T}(E+P)$ $D P$ showed higher internal resistance and higher compressive strength. The ECF pulp showed better results for tear index, higher viscosity and yield and fiber quality. It was concluded that the greater the amount of kaolin in paper, the lower its mechanical strength.
\end{abstract}

Keywords: Kaolin; Retention; Pulp Bleaching.

\footnotetext{
${ }^{1}$ Recebido em 24.02.2015 aceito para publicação em 21.10.2015.

${ }^{2}$ Universidade Estadual Paulista "Júlio de Mesquita Filho", Doutorado em Engenharia Mecânica, Itapeva, SP - Brasil. E-mail: <ivansantos.unesp@gmail.com>.

${ }^{3}$ Universidade Estadual Paulista "Júlio de Mesquita Filho", Campus de Itapeva, Itapeva, SP - Brasil. E-mail: < ventorim@itapeva.unesp.br $>$ e $<$ caraschi@itapeva.unesp.br>.

${ }^{4}$ Instituto Federal de São Paulo, IFSP- Campus Itapetininga, Itapetininga, SP - Brasil. E-mail: < jaquecomelato@hotmail.com>.
} 


\section{INTRODUÇÃO}

A incorporação de materiais minerais de baixa granulometria à suspensão de fibras celulósicas durante a formação do papel é técnica muito antiga e tornouse imprescindível para a obtenção de papéis de uso cada vez mais específico. A utilização de carga tem como finalidade básica diminuir o custo do papel, tendo em vista que seu valor é significativamente inferior ao da polpa celulósica, além de proporcionar maior uniformidade à superfície e melhorar características como alvura, lisura, opacidade, fornecendo ainda melhores condições para uma boa impressão (KUAN; BENAZZI, 1988). Os níveis de carga, em geral, variam de $5 \%$ a $25 \%$. Como os produtores do setor de papel estão sob crescente pressão financeira, existe potencial para reduzir os custos através da substituição da fibra com cargas. No entanto, isso só pode ser feito se as propriedades do papel, como resistência mecânica, propriedades óticas, entre outras, mantiverem seus valores em níveis aceitáveis. As principais cargas usadas são o caulim, o carbonato de cálcio e o talco. O caulim é a carga predominante, podendo ser empregado sozinho ou em combinação com outros tipos de cargas (IMERYS, 2008).

Caulim é definido como um minério composto de silicatos hidratados de alumínio, como a caulinita e a haloisita, que apresenta características especiais que permitem sua utilização no processo produtivo de papel, cerâmica, tintas etc. Também, podem ocorrer os minerais do grupo da caulinita, como diquita, nacrita, folerita, anauxita, colirita e tuesita (GOMES et al., 1996).

A retenção é fundamental na produção de papel. O objetivo do controle de retenção é regular a passagem de sólidos (fibras, finos e cargas) junto com água nas telas de formação do papel. A retenção também contribui com a diminuição da variabilidade da gramatura e do teor de cinzas ao longo do papel (D’ALMEIDA, 1988). A quantidade de finos na polpa aumenta a retenção de carga de minerais (FOELKEL, 2007). Esse autor ainda afirmou que o teor de finos contribui com as propriedades de resistência, bem assim com as propriedades óticas do papel.

Um dos fatores que influenciam a retenção de inorgânicos e as propriedades do papel é o processo de branqueamento, principalmente no que diz respeito a dimensões de fibra e teor de finos. Foelkel (2007) também reportou que a quantidade de finos na polpa aumenta a retenção de cargas minerais. Esse autor ainda afirmou que o teor de finos contribui com as propriedades de resistência, bem assim com as propriedades óticas do papel. O ponto negativo apontado pela pesquisa foi significativa redução na drenagem, de acordo com o aumento no teor de finos.

Almeida (2003) afirmou que o processo de branqueamento que utiliza maior carga alcalina em sua sequência gera maior teor de finos e maior degradação da polpa. Segundo Lin et al. (2007), a quantidade de finos presentes na polpa celulósica aumenta a retenção de cargas minerais. Esses autores ainda afirmaram que o teor de finos contribui com o aumento das propriedades de resistência, pois até certo teor aumenta o número de ligações interfibras, além de melhorar as propriedades óticas do papel. Kinoshita et al. (2000) verificaram que as partículas pequenas têm a capacidade de ocupar os espaços vazios não preenchidos pelos finos.

Com base no exposto, o objetivo deste estudo foi averiguar como a sequência de branqueamento influi na retenção de carga e como as propriedades do papel formado se comportam com o uso de diferentes teores de carga de caulim.

\section{MATERIAL E MÉTODOS}

A matéria-prima empregada neste estudo foi polpa industrial kraft de eucalipto, pré-deslignificada com oxigênio. As características iniciais da polpa foram: alvura de $60,7 \%$ ISO, viscosidade de $27,3 \mathrm{cP}$ e número kappa 11. Foram adotadas três sequências de branqueamento, sendo elas: $\mathrm{D}(\mathrm{E}+\mathrm{P}) \mathrm{DP}$ (referência, ECF), $\mathrm{A}_{\mathrm{HT}} \mathrm{D}(\mathrm{E}+\mathrm{P}) \mathrm{DP}$ (com hidrólise ácida, $\left.\mathrm{A}-\mathrm{ECF}\right) \mathrm{e}_{\mathrm{HT}} \mathrm{D}(\mathrm{E}+\mathrm{P}) \mathrm{P}$ (ECF-Light), em que $\mathrm{D}, \mathrm{A}_{\mathrm{HT}}$, $(\mathrm{E}+\mathrm{P})$ e $\mathrm{P}$ são siglas referentes aos estágios de dióxido de cloro, hidrólise ácida em alta temperatura, extração alcalina com peróxido de hidrogênio e peróxido de hidrogênio, respectivamente. Todas as sequências foram otimizadas para atingirem alvura final de $90 \pm 0,5 \%$ ISO.

O licor de branqueamento de cada estágio foi adicionado à polpa em temperatura ambiente. $\mathrm{O}$ requerimento de $\mathrm{NaOH}$ ou $\mathrm{H}_{2} \mathrm{SO}_{4}$ para controle de $\mathrm{pH}$ foi realizado em estudo prévio com miniamostras de polpa. Para cada estágio de branqueamento, foram extraídas amostras do licor residual para análises de $\mathrm{pH}$ e residual de reagente (quando aplicável). A polpa foi lavada com o equivalente a $9 \mathrm{~m}^{3}$ de água por tonelada seca de polpa. 
Tabela 1 - Condições gerais do branqueamento. Table 1 - General bleaching conditions.

\begin{tabular}{|c|c|c|c|c|c|c|}
\hline \multirow[t]{2}{*}{ Parâmetro } & \multicolumn{6}{|c|}{ Estágio de branqueamento } \\
\hline & $\mathrm{A}_{\mathrm{HT}}$ & $\mathrm{D}$ & $(\mathrm{E}+\mathrm{P})$ & $\mathrm{D}$ & $P$ & $\mathrm{P}^{*}$ \\
\hline Consistência, \% & 10 & 10 & 10 & 10 & 10 & 10 \\
\hline Temperatura, ${ }^{\circ} \mathrm{C}$ & 95 & 60 & 70 & 70 & 95 & 95 \\
\hline Tempo, $\min$ & 120 & 30 & 60 & 180 & 120 & 120 \\
\hline $\mathrm{H}_{2} \mathrm{O}_{2}, \mathrm{~kg} / \mathrm{t}$ & - & - & 3 & - & 6 & 20 \\
\hline $\mathrm{NaOH}, \mathrm{kg} / \mathrm{t}$ & - & - & 10 & - & 6 & 20 \\
\hline $\mathrm{H}_{2} \mathrm{SO}_{4}, \mathrm{~kg} / \mathrm{t}$ & 5 & 1 & - & - & - & - \\
\hline $\mathrm{ClO}_{2}\left(\mathrm{como} \mathrm{Cl}_{2}\right), \mathrm{kg} / \mathrm{t}$ & - & $* *$ & - & 12 & - & - \\
\hline Fator kappa & - & 0,2 & - & - & - & - \\
\hline $\mathrm{pH}$ final & 3,0 & 3,0 & 11,0 & 3,8 & 10,5 & 10,5 \\
\hline
\end{tabular}

*Estágio de peróxido de hidrogênio somente para a sequência ECF-Light.

**Dosado de acordo com o fator kappa. Na sequência ECF-Light, foram utilizados $10 \mathrm{~kg} / \mathrm{t}$.

As análises de número kappa, alvura e viscosidade da polpa foram efetuadas de acordo com os procedimentos descritos pelas Normas TAPPI T 236 om-99, TAPPI T 525 om-92 e TAPPI T 230 om-99, respectivamente. O rendimento da sequência de branqueamento foi determinado por gravimetria. Todos os ensaios foram realizados em duplicata.

As polpas foram refinadas a partir de curvas de refino em moinho PFI, conforme a Norma NBR ISO 5264$2: 2012$. Foi estabelecido que os testes físicos e mecânicos fossem realizados apenas para as polpas com $40^{\circ}$ Schopper-Riegler ( $\left.{ }^{\circ} \mathrm{SR}\right)$. Após o refino foram confeccionados os corpos de prova, conforme a Norma TAPPI T 205 sp-95. Não foi utilizado nenhum tipo de agente químico além de caulim e fibra na confecção das folhas. Portanto, após o refino foi adicionada à solução de polpa celulósica, durante o preparo do corpo de prova (folha) para testes físicos, a fração correspondente em massa para que a quantidade do caulim fosse equivalente a $5 \%, 10 \%, 15 \%, 20 \%, 25 \%$, $30 \%$ e $35 \%$ em massa do papel. O caulim foi primeiramente moído em um almofariz. Posteriormente, pesou-se a quantidade requerida em um béquer de $1,0 \mathrm{~L}$, e adicionaramse $700 \mathrm{~mL}$ de água destilada. A mistura ficou $20 \mathrm{~min}$ sob agitação. O caulim foi adicionado à polpa no desintegrador. Em teste prévio, observou-se, em microscópio, que as partículas de caulim após a agitação durante 20 min estavam totalmente dispersas.

As fibras da polpa celulósica livre de caulim foram analisadas em FQA (Fiber Quality Analyzer). Determinaram-se as seguintes dimensões: comprimento médio ponderado por comprimento de fibras, coarseness e teor de finos. Os ensaios físicos e mecânicos foram realizados de acordo com as normas-padrão, como segue: resistência ao rasgo (TAPPI T 414 om-98), resistência interna Scott-bond test (TAPPI T 569 pm-00), lisura Bekk (TAPPI T $479 \mathrm{~cm}-99$ ) e resistência à compressão short-span (TAPPI T 826 pm-92). Foram realizadas 10 repetições para cada ensaio.

Os resultados dos ensaios físicos foram analisados através de análise de variância (ANOVA) e teste de comparação de médias de Tukey a 5\% de significância (95\% de probabilidade).

\subsection{Determinação dos teores de celulose e hemiceluloses da polpa branqueada}

Os teores de celulose e hemiceluloses foram determinados a partir da polpa branqueada a $90 \%$ ISO, considerando a polpa composta de $100 \%$ de holocelulose para fins práticos. Em um béquer de $100 \mathrm{~mL}$, colocaramse $1,0000 \mathrm{~g}$ a.s. de holocelulose e $15,0 \mathrm{~mL}$ de hidróxido de potássio $24,0 \% \mathrm{~m} / \mathrm{m}$. Após $15 \mathrm{~h}$ sob agitação, filtrouse a mistura em funil de vidro sinterizado $\mathrm{n}^{\mathrm{o}} 1$ previamente tarado, lavando o precipitado com água destilada até a neutralidade. Em seguida, lavou-se com ácido acético $1,0 \%$ e, por último, com etanol em excesso. A celulose obtida foi seca ao ar ambiente por $48 \mathrm{~h}$ e em estufa a $105 \pm 3{ }^{\circ} \mathrm{C}$ por $30 \mathrm{~min}$ e, posteriormente, resfriada em dessecador. Determinou-se o teor de celulose $(\%$ Celulose) a partir da equação 1 , sendo $m_{1}$ a massa de celulose seca, em gramas; e $m_{2}$ é a massa de holocelulose seca, em gramas.

$$
\% \text { Celulose }=\frac{m_{1}}{m_{2}} \times 100
$$

Revista Árvore, Viçosa-MG, v.39, n.6, p.1147-1154, 2015

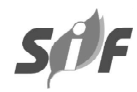


O teor de hemiceluloses foi calculado pela diferença entre holocelulose e celulose.

\section{RESULTADOS}

\subsection{Branqueamento}

Os resultados do processo de branqueamento quanto às características das polpas branqueadas são apresentados na Tabela 2 .

A polpa referência (ECF) apresentou maior teor de hemiceluloses $(17,2 \%)$, consequentemente maior rendimento, do que as outras duas polpas que apresentaram estágio de hidrólise ácida no branqueamento. As polpas que tiveram estágio de hidrólise ácida no branqueamento apresentaram entre elas diferença de $0,5 \%$ em seus teores.

Verificou-se que tanto a sequência referência quanto a sequência com estágio de hidrólise ácida necessitaram de 2.750 revoluções PFI para atingir $40^{\circ} \mathrm{SR}$, enquanto a sequência ECF-Light necessitou de 2.790 revoluções.

A polpa ECF-Light apresentou maior teor de cinzas que a A-ECF.

Na Tabela 3, observam-se os parâmetros obtidos para análise de fibras. Tanto na sequência A-ECF quanto na sequência ECF-Light, as polpas apresentaram menores dimensões de fibras e maiores teores de finos, em comparação com a polpa da sequência referência.

O comprimento de fibra apresentou diferenças de $5,5 \%$ na sequência com hidrólise ácida e de $7,4 \%$ na sequência ECF-Light, em comparação com o comprimento da fibra obtida pela sequência referência.

\subsection{Influência do branqueamento na retenção de caulim}

A Figura 1 representa a retenção de caulim em função do percentual mássico de caulim adicionado à polpa. A menor retenção foi encontrada no teor de $35 \%$ de caulim para todas as sequências. Quanto às sequências de branqueamento, constatou-se que a sequência ECF-Light foi a que apresentou maior retenção de caulim em todos os percentuais mássicos de enchimento do papel.

\subsection{Testes físicos e mecânicos}

Os resultados dos testes físicos e mecânicos para diferentes níveis de carga em papéis formados a partir das polpas produzidas por diferentes sequências de branqueamento são apresentados na Figura 2.

Na Figura 2, verificam-se os resultados de lisura para as polpas contendo de $0 \%$ a $35 \%$ de caulim. A análise de variância apontou para o teor de caulim interações significativas dos resultados. O teste de Tukey das diferenças entre médias mostrou que o processo de branqueamento não influenciou as sequências referência e A-ECF, mas as duas diferiram da sequência ECF-Light, que apresentou maior lisura, como mostrado na Figura 2. Verifica-se também, nessa figura, que de $0 \%$ a $20 \%$ a lisura tende a aumentar, e a partir desse ponto ela decresce nas três sequências de branqueamento, podendo representar o ponto

Tabela 2 - Características das polpas branqueadas.

Table 2 - Bleached pulp's characteristics.

\begin{tabular}{|c|c|c|c|}
\hline \multirow{2}{*}{ Resultados } & \multicolumn{3}{|c|}{ Sequências } \\
\hline & $\mathbf{D}(\mathbf{E}+\mathbf{P}) \mathbf{D P}(\mathrm{ECF})$ & $\mathbf{A}_{\mathbf{H T}} \mathbf{D}(\mathbf{E}+\mathbf{P}) \mathbf{D P}(\mathrm{A}-\mathrm{ECF})$ & $\mathbf{A}_{\mathbf{H T}} \mathbf{D}(\mathbf{E}+\mathbf{P}) \mathbf{P}(\mathrm{ECF}-$ Light $)$ \\
\hline Viscosidade, $\mathrm{cP}$ & 17,8 & 15,7 & 13,9 \\
\hline Alvura A. D., \%ISO & 90,5 & 90,1 & 86,6 \\
\hline Número kappa no estágio $(\mathrm{E}+\mathrm{P})$ & 4,4 & 3,2 & 4,8 \\
\hline Cloro ativo total, $\mathrm{kg} / \mathrm{ta} . \mathrm{s}$. & 4,3 & 4,7 & 6,2 \\
\hline $\mathrm{ClO}_{2}$ como $\mathrm{Cl}_{2}, \mathrm{~kg} / \mathrm{t}$ & 34,0 & 28,0 & 10,0 \\
\hline $\mathrm{H}_{2} \mathrm{O}_{2}, \mathrm{~kg} / \mathrm{t}$ & 9,0 & 9,0 & 25,0 \\
\hline $\mathrm{NaOH}, \mathrm{kg} / \mathrm{t}$ & 16,0 & 16,0 & 16,0 \\
\hline $\mathrm{H}_{2} \mathrm{SO}_{4}, \mathrm{~kg} / \mathrm{t}$ & 1,0 & 6,0 & 6,0 \\
\hline Revoluções PFI & 2750 & 2750 & 2790 \\
\hline Hemiceluloses, \% & 17,2 & 15,2 & 14,7 \\
\hline Cinzas, $\%$ & 0,24 & 0,16 & 0,20 \\
\hline Rendimento, \% & 96,6 & 94,3 & 94,1 \\
\hline
\end{tabular}

Revista Árvore, Viçosa-MG, v.39, n.6, p.1147-1154, 2015 
Tabela 3 - Resultados das dimensões de fibras. Table 3 -Results for fiber dimensions.

\begin{tabular}{lccc}
\hline \multirow{2}{*}{ Parâmetros } & \multicolumn{3}{c}{ Sequências } \\
\cline { 2 - 4 } & $\mathbf{D}(\mathbf{E}+\mathbf{P}) \mathbf{D P}(\mathrm{ECF})$ & $\mathbf{A}_{\mathbf{H T}} \mathbf{D}(\mathbf{E}+\mathbf{P}) \mathbf{D P}(\mathrm{A}-\mathrm{ECF})$ & $\mathbf{A}_{\mathbf{H T}} \mathbf{D}(\mathbf{E}+\mathbf{P}) \mathbf{P}(\mathrm{ECF}-$ Light $)$ \\
\hline Área, $\mathrm{mm}^{2}$ & 0,07 & 0,06 & 0,06 \\
Comprimento, mm & 0,54 & 0,53 & 0,50 \\
Teor de finos, \% & 7,5 & 9,8 & 12,2 \\
Coarseness, $\mathrm{mg} / 100 \mathrm{~m}$ & 8,9 & 8,4 & 8,1 \\
Incerteza, \% & 10,78 & 10,66 & 11,79 \\
\hline
\end{tabular}

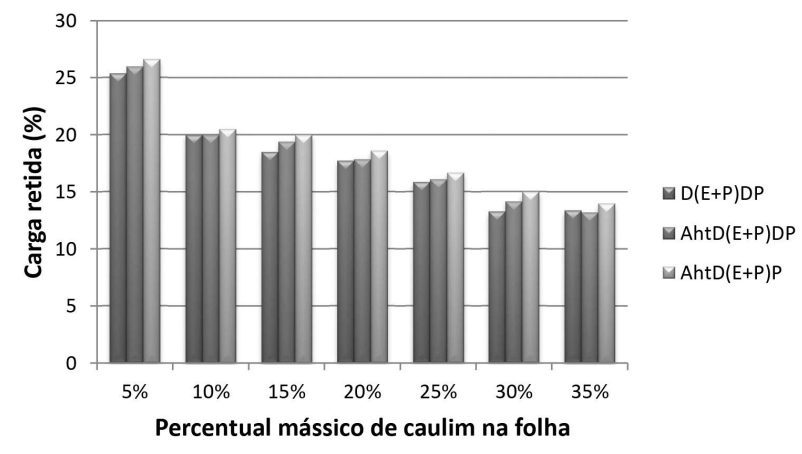

Figura 1 - Retenção de caulim para cada sequência de branqueamento.

Figure 1 -Kaolin's retention for each bleaching sequence.

onde a massa de caulim é máxima para a máxima lisura.

Quanto ao teste de compressão, verifica-se, na Figura 2, que a polpa A-ECF foi a que apresentou melhores resultados, e o teor de caulim influenciou apenas as quotas de $30 \%$ e $35 \%$. O teste de Tukey das diferenças entre médias mostrou que não houve diferenças entre a polpa referência e a polpa ECF-Light, e as duas diferiram da sequência A-ECF, como mostrado na Figura 2.

A partir de $20 \%$ de caulim, verifica-se a tendência de que as amostras apresentaram decadência, mostrando o mesmo comportamento observado na Figura 2.

A resistência interna das fibras, medida pelo método "Scott", conforme mostrado na Figura 2, foi maior nas amostras livres de caulim. A resistência interna não variou entre as três sequências em nenhum teor de caulim, segundo o teste de Tukey para diferença entre médias.

O teste de Tukey das diferenças entre médias indicou que as polpas obtidas da sequência referência, seguida da sequência A-ECF, apresentaram maior resistência ao rasgo do que a polpa ECF-Light, como mostrado na Figura 2.

\section{DISCUSSÃO}

Foi observado que a sequência referência apresentou maior viscosidade que as demais. Isso se deve ao fato de o dióxido de cloro ser um oxidante mais seletivo que o peróxido de hidrogênio (LOUREIRO et al., 2009), fazendo que as cadeias dos polissacarídeos sejam mais preservadas. Embora o estágio ácido apresente baixo rendimento quando comparado a outros estágios, apresenta também menor custo de reagente e menor demanda de cloro ativo total ( $\operatorname{como~} \mathrm{Cl}_{2}$ ), em comparação com a sequência ECF-Light, conforme observado na Tabela 2. Também são apresentadas as características finais de cada polpa, e a energia necessária para refino para obtenção de uma drenabilidade equivalente a $40^{\circ}$ $\mathrm{SR}$. Os resultados de alvura indicaram que somente a sequência ECF-Light não atingiu a alvura objetivo (90\% ISO).

A polpa obtida na sequência com estágio de hidrólise ácida apresentou menor número kappa após o estágio $(\mathrm{E}+\mathrm{P})$ do que as outras sequências. Uma vez que a única diferença entre as sequências é o estágio de hidrólise ácida, atribui-se, então, a esse estágio a diminuição do número kappa. E isso se deve ao fato de o estágio de hidrólise ácida remover os ácidos hexenurônicos e elementos metálicos que são muito significantes na determinação do número kappa.

A polpa que apresentou o menor teor de hemiceluloses foi a ECF-Light, devido à maior degradação dos polissacarídeos no estágio de peroxidação final.

Segundo Rosa (2003), as hemiceluloses são importantes causadoras de efeitos superficiais de ligações interfibras, além de providenciarem um auxílio nos processos de inchamento das fibras e de refino da polpa.

Revista Árvore, Viçosa-MG, v.39, n.6, p.1147-1154, 2015 


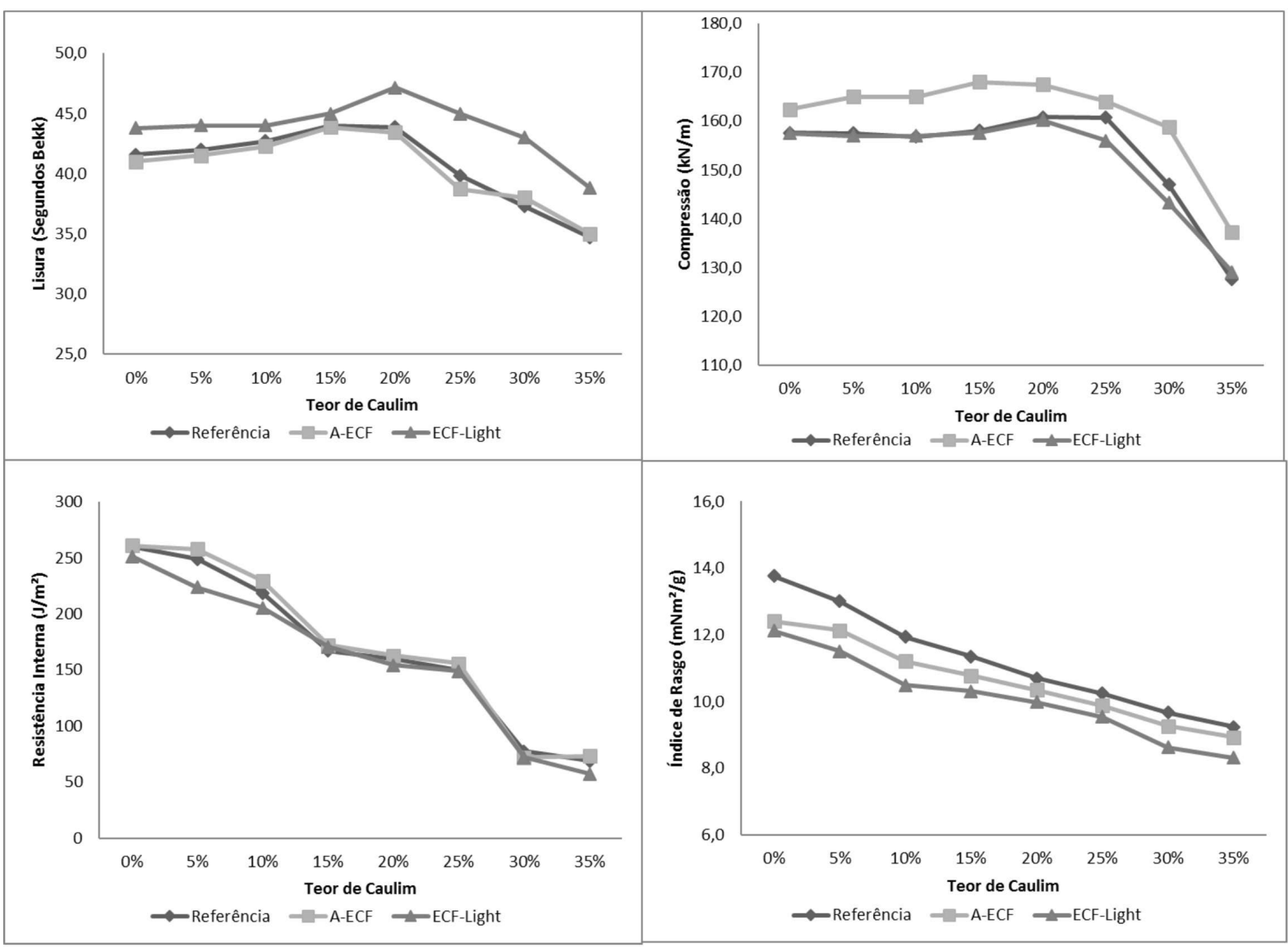

Figura 2 - Propriedades físico-mecânicas para diferentes teores de caulim.

Figure 2-Physical and mechanical properties for different amounts of kaolin.

A autora ressalta ainda que os efeitos das ligações entre as fibras para formação de papéis são altamente dependentes do teor de hemiceluloses que, por muitas vezes, dependendo da composição dos seus constituintes, pode modificar completamente o comportamento de determinada polpa e direcioná-la para uma nova utilização ou aplicação.

Verificou-se que tanto a sequência referência quanto a sequência A-ECF necessitaram de 2.750 revoluções PFI para atingir $40^{\circ} \mathrm{SR}$, enquanto a sequência ECFLight necessitou de 2.790 revoluções. Isso pode ser atribuído ao menor percentual de hemiceluloses que essa sequência apresenta (Tabela 2), pois as hemiceluloses facilitam o refino (FOELKEL, 2007). O teor de hemiceluloses, além de influenciar a refinabilidade da polpa, influi na resistência do papel e aumenta o contato interfibrilar, formando, assim, maior número de ligações de hidrogênio, um dos fatores responsáveis pela resistência do papel.

Segundo Costa et al. (1997), as cinzas na madeira são geralmente constituídas pelos íons cálcio, manganês, ferro, magnésio, cobre, alumínio, potássio, sódio etc. e, normalmente, são encontrados na forma de silicatos, carbonatos, fosfatos e sulfatos. Após o branqueamento, parte dessas substâncias é eliminada da polpa. O menor teor de cinzas nas polpas que passaram por hidrólise ácida é explicado pelo fato de que esse estágio remove metais. A polpa ECFLight apresentou maior teor de cinzas que a A-ECF, porque teve maior dosagem de peróxido de hidrogênio no último estágio e, consequentemente, maior dosagem de soda. Nem todo sódio é removido da polpa durante a lavagem, refletindo, assim, no resultado de teor de cinzas nessa polpa. 
A diferença de tamanho de fibras nessas duas sequências é explicada pela maior degradação gerada pelo último estágio da sequência ECF-Light. Podese atribuir a diferença de largura de $9,3 \%$ entre a sequência referência e a sequência ECF-Light à degradação causada pelo estágio de peroxidação com alta dosagem no final da sequência ECF-Light, pois o peróxido de hidrogênio é pouco seletivo e degrada os polissacarídeos, diminuindo, assim, a largura da fibra.

Um reflexo da baixa seletividade do peróxido de hidrogênio é o maior teor de finos gerado nessa sequência, em comparação com o teor de finos gerado pela sequência referência, pois, quanto maior a degradação da polpa, maior o teor de finos gerado. Quanto menor a seletividade do reagente, maior deve ser a geração de finos na polpa. A sequência com estágio de hidrólise ácida apresentou 9,8\% de finos em sua polpa final diante de $7,5 \%$ de finos gerados pela sequência referência.

Os resultados das três polpas indicaram que, quanto maior a dimensão da fibra, maior o coarseness. Foelkel (2007) mencionou que valores entre 9 e $11 \mathrm{mg} / 100 \mathrm{~m}$ de fibras de eucalipto branqueadas são considerados altos e valores entre 4,5 e $6 \mathrm{mg} / 100 \mathrm{~m}$, baixos. Como os resultados das polpas oscilaram entre 8,1 e 8,9 , consideram-se os valores obtidos como altos.

Santos et al. (2014) encontraram que, para a adição de $20 \%$ de caulim, a retenção foi maior para a sequência ECF-Light, devido ao maior comprimento de fibras e à porcentagem de finos.

Pode-se atribuir a maior retenção das sequências que sofreram maior degradação ao fato de elas apresentarem menor dimensão de fibra e maior teor de finos, implicando maior número de ligações entre fibras (LIN et al., 2007). Também, os finos podem reter mais carga através de ligações químicas (LIIMATAINEN et al., 2006).

As elevadas lisuras encontradas em todas as amostras se devem à melhor consolidação do papel devido ao teor de finos produzido durante o refino, pois este preenche os poros, formando uma folha com alta lisura (KROGERUS; FAGERHOLM, 2002; LEE et al., 2011).

Bundy e Ishley (1991) verificaram que a presença de caulim como preenchimento do papel diminui substancialmente a resistência entre as fibras devido à baixa interação das fibras com o caulim na ausência de agentes aglutinantes. O aumento do volume específico aparente do papel causado pela presença do caulim na amostra é o principal fator para a redução de resistência do papel.

Esse menor valor encontrado pode ser referente ao menor comprimento de fibras, pois, segundo a literatura (PAGE, 1994; KINOSHITA et al., 2000), a resistência ao rasgo é fortemente influenciada pelo comprimento das fibras do papel. Kinoshita et al. (2000) verificaram que a resistência ao rasgo do papel diminui com o incremento de carga na massa, pois, ao aumentar a densidade de partículas na folha, diminuem as ligações entre fibras, devido à redução da área de contato entre elas, o que reduz a resistência das ligações de contato.

D’Almeida (1988 citado por ALMEIDA, 2003) afirmou que o comprimento de fibra é uma dimensão importante no desenvolvimento de resistência ao rasgo, pois reflete a resistência intrínseca das fibras, relacionadas à espessura de parede celular. Quanto maior o comprimento, maior a resistência intrínseca e maior a resistência ao rasgo.

\section{CONCLUSÕES}

- As propriedades das fibras da polpa celulósica sofreram variação em razão da degradação causada pelas diferentes sequências de branqueamento, sendo possível constatar que o processo de branqueamento trouxe fatores positivos e negativos à qualidade final das polpas. A polpa que apresentou maiores dimensões de fibras foi a referência, e as sequências de branqueamento ECF e A-ECF apresentaram maiores dimensões de fibra do que a polpa ECF-Light.

- A polpa ECF-Light apresentou melhores valores de retenção do que as outras sequências devido ao maior teor de finos apresentado. A polpa ECF-Light também obteve melhores resultados de lisura.

- A polpa A-ECF apresentou melhores resultados de resistência interna e de resistência à compressão. A adição de caulim em teores acima de $20 \%$ provocou queda nas propriedades de resistência mecânica do papel.

\section{AGRADECIMENTOS}

Ao Conselho Nacional de Desenvolvimento Científico e Tecnológico (CNPq), pelo apoio financeiro.

Revista Árvore, Viçosa-MG, v.39, n.6, p.1147-1154, 2015 


\section{REFERÊNCIAS}

ALMEIDA, F.S. Influência da carga alcalina no processo de polpação losolids para madeiras de eucalipto. 2003. 115f. Dissertação (Mestrado em Ciências Florestais) - Escola Superior de Agricultura "Luiz de Queiroz", Universidade de São Paulo, Piracicaba, 2003.

BUNDY, W.M.; ISHLEY, J.N. Kaolin in paper filling and coating. Applied Clay Science, v.5, n.5/ 6, p.397-420, 1991.

COSTA, M.M.; COLODETTE, J.L. Efeito da composição química da polpa $\mathrm{Kraft} \mathrm{O}_{2}$ na sua branqueabilidade. In: CONGRESSO ANUAL DE CELULOSE E PAPEL, 34. 1997, São Paulo. Anais... São Paulo: ABTCP, 1997. p.1-17.

D’ALMEIDA, M.L.O. Composição química dos materiais lignocelulósicos. IPEF Celulose e Papel, v.1. n.1, p.6-38, 1988.

FOELKEL, C. As fibras dos eucaliptos e as qualidades requeridas na celulose kraft para a fabricação de papel. Eucalyptus online. 2007. 48p. Disponível em http://www.eucalyptus.com.br/ capitulos/PT03 fibras.pdf. Acesso em: 20 jan. 2015.

GOMES, M.T.O.; FERNANDES, P.C.S.; VALENÇA, A.C.V. Caulim para Revestimentos de Papéis e Cartões. Disponível em: www.bndes.gov.br/conhecimento/bnset/caulim. Acesso em: 02 de fev.de 2015.

IMERYS TECHNICAL GUIDE. Effect of Fillers on LWC. Georgia: 2008. p.1-4. (IMERYS Pigments for paper).

KINOSHITA, N.; KATSUZAWA, H.; NAKANO, S.; MURAMATSU, H.; SUZUKI, J.; IKUMI, Y.; TOYOTAKE, Y. Influence of fiber length and filler particle size on pore structure and mechanical strength of filler-containing paper. The

Canadian Journal of Chemical Engineering, v.78, n.5, p.974-982, 2000.
KROGERUS, B.; FAGERHOLM, K. Fines from different pulps compared by image analysis. Nordic Pulp and Paper Research Journal, v.17, n.4, p.440-444, 2002.

KUAN, G.S.S.; BENAZZI, R.C. Tecnologia de fabricação do papel. 2. ed. São Paulo: USP, 1988. v. 2, p. 758-796.

LIIMATAINEN, H.; KOKKO, S.; ROUSU, P.; NIINIMAKI, J. Effect of PCC Filler on Dewatering of Fiber Suspension. Tappi Journal, v.5, n.11, p.11-17, 2006.

LIN, T.; YIN, X.; RETULAINEN, E.; NAZHAD, M. $M$. Effect of chemical pulp fines on filler retention and paper properties. Appita Journal, v.60, n.6, p.469-473, 2007.

LEE, H.; NAM, W.S.; SOHN, S.D.; PAIK, K.H. Effect of different types of fines on the properties of recycled chemical pulp. Journal of Industrial and Engineering Chemistry, v.17, n.1, p.100-104, 2011.

LOUREIRO, P.E.G.; ANTUNES, J.M.C.; FERREIRA, L.M.G.A.; EVTUGUIN, D.V.; CARVALHO, M.G.V.S. Comparação das cinéticas de branqueamento no estágio final de peróxido de hidrogênio das sequências de branqueamento $\mathrm{DE}_{\mathrm{OP}} \mathrm{DP}$ e OQ(PO)DP. O Papel, v.70, p.56-68, 2009.

PAGE, D.H. A note on the mechanism of tearing strength. TAPPI Journal, v.3, n.77, p.201-203, 1994.

ROSA, C.A.B. Influência do Teor de Lignina da Madeira de Eucalyptus globulus na produção e na qualidade da celulose Kraft. 2003. 150f. Dissertação (Mestrado em Engenharia Florestal) - Universidade Federal de Santa Maria, Santa Maria, 2003.

SANTOS, I.R.; VENTORIM, G.; CARASCHI, J.C.; FAVARO, J.S.C.. Impacto da adição de caulim nas propriedades físico-mecânicas do papel formado por sequências ECF. Cerne, v.20, n.2, p.231-238, 2014. 